\title{
Association of Lipids' Metabolism with Vitamin D Receptor (rs10735810, rs222857) and Angiotensinogen (rs699) Genes Polymorphism in Essential Hypertensive Patients
}

\author{
Yuliya Repchuk $^{1 *(\mathbb{D})}$, Larysa Sydorchuk ${ }^{1}$ (D) Larysa Fedoniuk ${ }^{2}$ (D) Zoia Nebesna $^{2}$ (D), Valentyna Vasiuk ${ }^{3}$ (D) Andrii Sydorchuk ${ }^{1}$ (D) \\ Oksana Iftoda ${ }^{1}$ (D) \\ ${ }^{1}$ Department of Family Medicine, Bukovinian State Medical University, Chernivtsi, Ukraine; ${ }^{2}$ Department of Biology, Ternopil National \\ Medical University, Ternopil, Ukraine, ${ }^{3}$ Department of Internal Disease, Bukovinian State Medical University, Chernivtsi, Ukraine
}

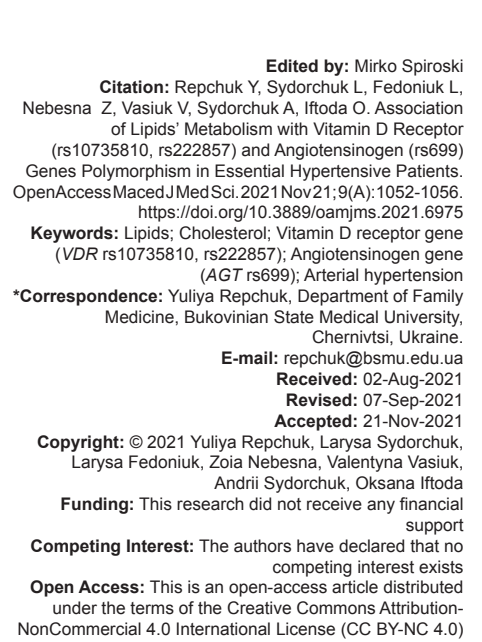

Introduction

Cardiovascular (CV) diseases are the most spread cause of mortality in the world and it is responsible for $>4$ million deaths in Europe each year [1]. Essential arterial hypertension $(E A H)$ has a high prevalence and is a major risk factor for the development of $\mathrm{CV}$ diseases [2]. Hypertension affects over 1.2 billion individuals worldwide and has become the most critical and expensive public health problem [3]. Higher the long-term level of blood pressure (BP), greater the chances of hypertension complications, such as myocardial infarction, renal failure, stroke, and heart failure [4]. Reducing BP in patients with $E A H$ is the most effective way to lower the mortality rates and hypertension-mediated organ damage [5].

$\mathrm{EAH}$ is a multifactorial disease involving environmental and genetic factors together with riskconferring behaviors. EAH infrequently befalls in isolation and often combines with other $\mathrm{CV}$ risk factors such as dyslipidemia and glucose intolerance, or other metabolic disorders evidence [6], [7]. Obesity, lack of physical activity, and excessive salt intake are the most well-known environmental factors associated with $\mathrm{EAH}$. An increased risk of $\mathrm{CV}$ complications is associated with dyslipidemia as well [8]. It plays an important role in the formation of the atherosclerotic lesions of the arteries in general including the kidneys and cardiac muscle [1]. The lipids' level in the blood plasma is considerably determined by genetic factors. In general, the inheritance model in patients with dyslipidemia is not indicative of the fact that there is one disorder with one gene (monogenic) causing pathology. It must originate from the inheritance of more than 1 variant of a gene that affects lipoprotein metabolism, which in itself may have a relatively small effect, but in combination with one or the other has a greater effect on triglycerides (TGs) or high-density lipoprotein cholesterol (HDL-C). The inheritance pattern is polygenic [9]. A pathogenic genes 
part such as the apolipoprotein (APO) family - APOA, $A P O B$, and APOE is the most studied, but several others are requiring further investigations.

\section{Methods}

\section{Ethical approval}

This study conforms to international bioethical standards (European Convention on Human Rights and Biomedicine, the WMA Declaration of Helsinki on ethical principles of scientific medical research involving human subjects, GCP, EUC directive \#609) and approved by Commission for Bioethics in Research of the Bukovinian State Medical University, Ukraine. All patients signed written permissions and obtained full information about the study before participation.

\section{Selection and description of participants}

The single-stage study involved 100 patients. Among them, 21\% (21) were men and 79\% (79) were women, an average age $59.86 \pm 6.22$ years old (y o). The control group included 60 practically healthy individuals of an appropriate age and sex distribution.

\section{Inclusion criteria}

EAH patients were included in the current study with hypertension-mediated organ damage (target organs damage $-2^{\text {nd }}$ severity stage, asymptomatic disease), from the $1^{\text {st }}$ through to the $3^{\text {rd }}$ grade of $\mathrm{BP}$ values; moderate-high CV risk; age above 30 y o. All enrolled subjects signed a consent form to participate in the study.

\section{Exclusion criteria}

Have been described in our former publications [6], [7], [10], [11]: We excluded patients with EAH Stage 3 (identified CV disease); chronic heart failure higher than II functional class (NYHA III-IV), EAH patients with complications of hypertension-mediated organ damage; secondary $\mathrm{AH}$; diabetes mellitus type I (DM 1), sub- and decompensated DM 2 (with diabetes target organ damage); malignant or uncontrolled $\mathrm{AH}$; sub- and decompensated diseases of the liver (3 times over the norm level of aspartate aminotransferase, alanine aminotransferase); bronchial asthma, chronic obstructive pulmonary disease of III-IV stage with C or D risk value (Gold, 2019); exacerbated infectious diseases or during unstable remission; psychological disorders; the oncologic problem of any location; taking oral corticosteroids or contraceptives; and pregnancy or lactation period.

\section{Genotyping analysis}

To examine the VDR gene (rs10735810, rs2228570) and AGT gene (704 rs699) polymorphism, a qualitative real-time polymerase chain reaction was made. The lymphocytes isolated from the peripheral venous blood stabilized by EDTA were used as the material for the study. The lymphocytes' DNA was isolated and purified according to the Thermo Scientific GeneJET Genomic DNA Purification Kit instructions (Thermo Fisher Scientific, USA) as it was described in our former publications [6], [7], [10], [11]. Amplification and genotyping were conducted on the device CFX96 Touch $^{\mathrm{TM}}$ (Bio-Rad Laboratories, Inc., USA) with the use of specific complementary probes TaqMan. The software of the thermal cycler CFX96 registered the melting temperature of TaqMan probes considering fluorescence marks Fam (the samples which are homozygous for VDR gene A allele and AGT gene $\mathrm{C}$ allele on Fam canal) and Hex (the samples which are homozygous for VDR gene $\mathrm{G}$ allele and AGT gene $T$ allele on Hex canal).

Plasma lipids included total cholesterol (TC), HDL-C, low-density lipoprotein cholesterol (LDL- C), and TGs assessment using BioSystem S.A. reagents (Spain), on a chemiluminescent analyzer "ACCENT-200" (Poland). As "target" lipids' levels were taken as follows, according to the European and National Guidelines recommendation: $\mathrm{TC}<5.0 \mathrm{mmol} / \mathrm{l}$ for persons with moderate CV risk, $<4.5$ $\mathrm{mmol} / \mathrm{l}$ for persons with high CV risk, $<4.0 \mathrm{mmol} / \mathrm{l}$ for persons with extremely high $\mathrm{CV}$ risk; LDL-C $<3.0 \mathrm{mmol} / \mathrm{l}$ for persons with moderate CV risk, $<2.5 \mathrm{mmol} / \mathrm{l}$ - for high CV risk, <1.8 mmol/l - for extremely high CV risk; TGs generally $<1.7 \mathrm{mmol} / \mathrm{l}$; and HDL-C $>1.02 \mathrm{mmol} / \mathrm{l}$ for men and $>1.2 \mathrm{mmol} / \mathrm{l}$ for women [12].

\section{Statistical analysis}

Statistical analysis was performed using StatSoft Statistica 7.0 (USA) software. Estimation of the sample sets difference was performed using an odd Student's t-criterion. Analysis of qualitative data (categorical variables) and risk of pathology development were assessed by a binary logistic regression model using relative risk (ReIR); risk ratio was estimated by odds ratio (OR) with $95 \%$ confidence interval $[95 \% \mathrm{Cl}]$ using a Chi-square test $\left(\chi^{2}\right)(\mathrm{df}=1)$. The difference was considered reliable with $p<0.05$.

\section{Results}

The genotype distribution depending on VDR and $A G T$ genes polymorphic variants in the control group and in the group of patients with EAH did not differ reliably (Tables 1 and 2). More than half of patients in both groups 
Table 1: Parameters of lipid metabolism depending on VDR gene (rs10735810, rs2228570) polymorphism, $\mathrm{M} \pm \mathrm{m}$

\begin{tabular}{lllllll}
\hline Group & Genotype & Sex & TC, $\mathrm{mmol} / \mathrm{L}$ & $\begin{array}{l}\text { TGs, } \\
\mathrm{mmol} / \mathrm{L}\end{array}$ & $\begin{array}{l}\mathrm{HDL}-\mathrm{C}, \\
\mathrm{mmol} / \mathrm{L}\end{array}$ & $\begin{array}{l}\mathrm{LDL}-\mathrm{C}, \\
\mathrm{mmol} / \mathrm{L}\end{array}$ \\
\hline $\begin{array}{llllll}\text { Control, } \\
\mathrm{n}=60\end{array}$ & $\mathrm{AA}, \mathrm{n}=18$ & $\mathrm{M}$ & $5.92 \pm 0.53$ & $1.89 \pm 0.68$ & $1.17 \pm 0.21$ & $4.53 \pm 0.47$ \\
& & $\mathrm{~F}$ & $5.93 \pm 0.87$ & $1.71 \pm 0.44$ & $1.43 \pm 0.1$ & $4.3 \pm 0.93$ \\
& $\mathrm{AG}, \mathrm{n}=28$ & $\mathrm{M}$ & $5.48 \pm 0.65$ & $1.76 \pm 0.38$ & $1.32 \pm 0.33$ & $3.85 \pm 0.45$ \\
& $\mathrm{~F}$ & $5.49 \pm 0.53$ & $1.49 \pm 0.43$ & $1.58 \pm 0.25$ & $3.76 \pm 0.5$ \\
& $\mathrm{GG}, \mathrm{n}=14$ & $\mathrm{~F}$ & $5.2 \pm 0.43$ & $1.67 \pm 0.31$ & $1.51 \pm 0.2$ & $3.63 \pm 0.4$ \\
& & & & & $\mathrm{P}_{\mathrm{AA}}=0.04$ \\
Patients, & $\mathrm{AA}, \mathrm{n}=23$ & $\mathrm{M}$ & $4.57 \pm 0.34$ & $2.34 \pm 0.36$ & $1.16 \pm 0.17$ & $3.12 \pm 0.32$ \\
$\mathrm{n}=100$ & & & $\mathrm{p}=0.006$ & & & $\mathrm{p}=0.003$ \\
& & $\mathrm{~F}$ & $6.08 \pm 0.44$ & $2.0 \pm 0.39$ & $1.31 \pm 0.25$ & $4.59 \pm 0.41$ \\
& $\mathrm{AG}, \mathrm{n}=50$ & $\mathrm{M}$ & $5.73 \pm 0.53$ & $2.36 \pm 0.4$ & $1.06 \pm 0.15$ & $4.47 \pm 0.52$ \\
& & & $\mathrm{p}_{\mathrm{AA}}=0.02$ & & & $\mathrm{p}_{\mathrm{AA}}=0.006$ \\
& & $\mathrm{~F}$ & $5.65 \pm 0.41$ & $1.9 \pm 0.35$ & $1.3 \pm 0.17$ & $4.07 \pm 0.37$ \\
& & & $\mathrm{p}_{\mathrm{AA}}=0.001$ & & $\mathrm{p}=0.04$ & $\mathrm{p}_{\mathrm{AA}}=0.002$ \\
& $\mathrm{GG}, \mathrm{n}=27$ & $\mathrm{M}$ & $5.55 \pm 0.34$ & $1.74 \pm 0.23$ & $1.2 \pm 0.21$ & $4.13 \pm 0.32$ \\
& & & & & & $\mathrm{p}_{\mathrm{AA}}=0.04$ \\
& & $\mathrm{~F}$ & $5.33 \pm 0.41$ & $1.85 \pm 0.3$ & $1.32 \pm 0.19$ & $3.91 \pm 0.36$ \\
& & & $\mathrm{p}_{\mathrm{AA}}=0.03$ & & & $\mathrm{p}_{\mathrm{AA}}=0.03$ \\
\hline
\end{tabular}

M: Males; F: Females; TC: Total cholesterol; TGs: Triglycerides; HDL-C: High-density lipoprotein cholesterol; LDL-C: Low-density lipoprotein cholesterol; P - The significance of differences with a control group of the same genotype; $p_{A A}-$ The significance of differences with AA genotype carriers in a particular group (control/ patients).

were heterozygous which corresponds to the normal Hardy-Weinberg equilibrium distribution. Subjects' distribution in the groups by age and gender did not differ reliably depending on genotype either $(p>0.05)$.

Table 2: Parameters of lipid metabolism depending on AGT gene (rs699) polymorphism, M $\pm \mathrm{m}$

\begin{tabular}{|c|c|c|c|c|c|c|}
\hline Group & Genotype & Sex & $\mathrm{TC}, \mathrm{mmol} / \mathrm{L}$ & TGs, mmol/L & $\begin{array}{l}\mathrm{HDL}-\mathrm{C} \text {, } \\
\mathrm{mmol} / \mathrm{L}\end{array}$ & $\begin{array}{l}\mathrm{LDL}-\mathrm{C} \text {, } \\
\mathrm{mmol} / \mathrm{L}\end{array}$ \\
\hline \multirow{7}{*}{$\begin{array}{l}\text { Control, } \\
\mathrm{n}=48\end{array}$} & \multirow[t]{2}{*}{$\mathrm{TT}, \mathrm{n}=8$} & $M$ & $4.65 \pm 0.37$ & $1.89 \pm 0.13$ & $0.91 \pm 0.08$ & $3.72 \pm 0.33$ \\
\hline & & $\mathrm{F}$ & $5.45 \pm 0.17$ & $1.67 \pm 0.06$ & $1.7 \pm 0.01$ & $3.77 \pm 0.09$ \\
\hline & \multirow[t]{3}{*}{$\mathrm{TC}, \mathrm{n}=25$} & M & $6.14 \pm 0.34$ & $1.58 \pm 0.58$ & $1.2 \pm 0.14$ & $4.75 \pm 0.31$ \\
\hline & & & $P_{T T}=0.02$ & & $P_{T T}=0.03$ & $P_{T T}=0.04$ \\
\hline & & $\mathrm{F}$ & $5.55 \pm 0.86$ & $1.64 \pm 0.47$ & $\begin{array}{l}1.43 \pm 0.1 \\
\mathrm{P}_{\pi}<0.001\end{array}$ & $3.97 \pm 0.38$ \\
\hline & \multirow[t]{2}{*}{ CC, $n=15$} & M & $5.7 \pm 0.53$ & $2.44 \pm 1.06$ & $1.56 \pm 0.5$ & $3.49 \pm 0.19$ \\
\hline & & $\mathrm{F}$ & $5.52 \pm 0.41$ & $1.83 \pm 0.42$ & $1.61 \pm 0.31$ & $\begin{array}{l}P_{T C}=0.002 \\
3.74 \pm 0.29\end{array}$ \\
\hline \multirow{8}{*}{$\begin{array}{l}\text { Patients, } \\
n=72\end{array}$} & \multirow[t]{2}{*}{$\mathrm{TT}, \mathrm{n}=10$} & M & $5.2 \pm 0.33$ & $2.05 \pm 0.54$ & $0.87 \pm 0.06$ & $3.88 \pm 0.14$ \\
\hline & & $\mathrm{F}$ & $5.73 \pm 0.46$ & $2.04 \pm 0.39$ & $1.3 \pm 0.18$ & $4.17 \pm 0.47$ \\
\hline & \multirow[t]{3}{*}{$\mathrm{TC}, \mathrm{n}=43$} & M & $5.79 \pm 0.14$ & $2.37 \pm 0.41$ & $1.1 \pm 0.15$ & $4.45 \pm 1.17$ \\
\hline & & & & $p=0.03$ & $P_{T T}=0.01$ & \\
\hline & & $\mathrm{F}$ & $5.99 \pm 0.39$ & $2.06 \pm 0.38$ & $1.29 \pm 0.17$ & $4.45 \pm 0.66$ \\
\hline & \multirow[t]{3}{*}{$\mathrm{CC}, \mathrm{n}=19$} & M & $5.02 \pm 0.36$ & $1.81 \pm 0.24$ & $1.22 \pm 0.26$ & $3.68 \pm 0.53$ \\
\hline & & & & & $P_{T T}=0.03$ & \\
\hline & & $\mathrm{F}$ & $5.52 \pm 0.56$ & $\begin{array}{l}1.43 \pm 0.28 \\
\mathrm{P}_{T C}=0.02\end{array}$ & $1.36 \pm 0.59$ & $4.06 \pm 0.48$ \\
\hline
\end{tabular}

M: Males; F: Females; TC: Total cholesterol; TGs: Triglycerides; HDL-C: High-density lipoprotein cholestero/; LDL-C: Low-density lipoprotein cholesterol; P - The significance of differences with a control group of the same genotype; PTT, pTC - The significance of differences with TT, TC genotypes carriers in a particular group (control/patients).

Lipid metabolism parameters considering VDR gene polymorphic variants are presented in Table 1. The parameters different from those of the normal values were found both in the control group and patients with $\mathrm{EAH}$. Increased TC levels (in $76.7 \%$ of subjects in the control group and $67 \%$ of patients with EAH) and LDL cholesterol (83.3\% and $89 \%$, respectively) were found.

The men carriers of AA genotype suffering from $\mathrm{EAH}$ presented $22.8 \%$ lower TC than in the control group ( $p=0.006$ ) and $20.2 \%$ lower in comparison with the AG genotype carriers ( $p=0.02$ ). The women AA genotype carriers with EAH had $25.4 \%$ higher TC level in comparison with GG genotype carriers' women ( $p=0.03)$.

Similar situation was observed with the LDL-C level: Male patients, AA genotype carriers, presented $31.1 \%$ lower values in comparison with the control group ( $p=0.003$ ); the difference with $A G$ and GG genotypes patients carriers was $30.2 \%$ and $24.5 \%$, respectively ( $p=0.006$ and $p=0.04)$. On the contrary, AA genotype women carriers possessed $12.8 \%$ $(p=0.002)$ and $17.4 \%(p=0.03)$ higher LDL-C values in comparison with the $A G$ and $G G$ genotype carriers.

The TGs and HDL-C levels did not differ reliably between the VDR gene polymorphic variants.

Considering the above parameters, $G$ allele of the VDR gene can be suggested to be associated with the TC and LDL-C levels elevation in men; AA genotype is associated with an increased level of these parameters in women.

The parameters of lipid metabolism considering AGT gene polymorphic variants are presented in Table 2. The TC mean values were higher than that of the normal ones practically in all the groups. The highest parameters were found in the TC genotype carriers, especially among men of the control group - $6.14 \pm 0.34 \mathrm{mmol} / \mathrm{L}$ versus $5.79 \pm 0.14 \mathrm{mmol} / \mathrm{L}$ in patients with $\mathrm{EAH}$, though there was no reliable difference found. The TGs level was higher in the T allele carriers (especially TC genotype) in comparison with the control group by $50 \%$ among men $(p=0.03)$ and $25.6 \%$ among women. The HDL-C level was lower in the TT genotype men carriers in both groups than that of the threshold, while the $\mathrm{C}$ allele carriers (especially CC genotype) had $26.4 \%(p=0.01)$ and $40.2 \%(p=0.03)$ higher values in comparison with the TT genotype carriers. The LDL-C parameters were the highest among the TC genotype carriers, but in comparison with other genotypes carriers, there was no reliable difference found.

Thus, the T allele of the AGT gene (rs699) can be suggested to be associated with the lower HDL-C level in men and an increased TGs level.

Assessment of the EAH risks considering lipid metabolism parameters and VDR gene polymorphism is shown in Table 3. The EAH risk increases as far as

Table 3: Lipids values as predictors of essential arterial hypertension in observed population depending on VDR gene (rs10735810, rs2228570) polymorphism

\begin{tabular}{|c|c|c|c|c|c|}
\hline \multirow[t]{2}{*}{ Potential risk factor } & \multicolumn{5}{|c|}{ Parameters } \\
\hline & $\overline{R R}$ & $95 \%$ Cl RR & OR & $95 \%$ CI RR & $p$ \\
\hline \multicolumn{6}{|l|}{ AA genotype } \\
\hline$\uparrow \mathrm{TC}$ & 1.08 & $0.84-1.38$ & 1.6842 & $0.27-10.43$ & $>0.05$ \\
\hline$\uparrow$ TGs & 0.94 & $0.53-1.66$ & 0.87 & $0.25-3.01$ & $>0.05$ \\
\hline$\downarrow$ HDL-C & 1.96 & $0.73-5.22$ & 2.69 & $0.67-10.74$ & $>0.05$ \\
\hline$\uparrow$ LDL-C & 1.03 & $0.84-1.26$ & 1.31 & $1.67-10.35$ & $>0.05$ \\
\hline \multicolumn{6}{|l|}{ AG genotype } \\
\hline$\uparrow \mathrm{TC}$ & 0.95 & $0.70-1.29$ & 0.85 & $0.31-2.34$ & $>0.05$ \\
\hline$\uparrow \mathrm{TGs}$ & 1.68 & $0.87-3.23$ & 2.3 & $0.86-6.21$ & $>0.05$ \\
\hline$\downarrow$ HDL-C & 1.77 & $0.80-3.92$ & 2.25 & $0.77-6.54$ & $>0.05$ \\
\hline$\uparrow$ LDL-C & 1.05 & $0.88-1.25$ & 1.5 & $0.37-6.11$ & $>0.05$ \\
\hline \multicolumn{6}{|l|}{ GG genotype } \\
\hline$\uparrow$ TC & 0.73 & $0.44-1.19$ & 0.43 & $0.11-1.72$ & $>0.05$ \\
\hline$\uparrow \mathrm{TGs}$ & 0.78 & $0.48-1.25$ & 0.5 & $0.13-2.0$ & $>0.05$ \\
\hline$\downarrow$ HDL-C & 2.33 & $0.58-9.36$ & 3.0 & $0.55-16.38$ & $>0.05$ \\
\hline$\uparrow$ LDL-C & 1.19 & $0.83-1.72$ & 2.3 & $0.48-11.08$ & $>0.05$ \\
\hline \multicolumn{6}{|l|}{ A allele } \\
\hline$\uparrow \mathrm{TC}$ & 0.93 & $0.75-1.14$ & 0.74 & $0.31-1.76$ & $>0.05$ \\
\hline$\uparrow \mathrm{TGs}$ & 1.37 & $0.9-2.08$ & 1.78 & $0.84-3.78$ & $>0.05$ \\
\hline$\downarrow$ HDL-C & 1.83 & $0.99-3.37$ & 2.37 & $1.02-5.51$ & 0.04 \\
\hline$\uparrow$ LDL-C & 1.04 & $0.91-1.19$ & 1.41 & $0.44-4.51$ & $>0.05$ \\
\hline \multicolumn{6}{|l|}{ G allele } \\
\hline$\uparrow \mathrm{TC}$ & 0.87 & $0.67-1.13$ & 0.66 & $0.29-1.49$ & $>0.05$ \\
\hline$\uparrow \mathrm{TGs}$ & 0.98 & $0.64-1.52$ & 0.97 & $0.43-2.17$ & $>0.05$ \\
\hline$\downarrow$ HDL-C & 1.91 & $0.96-3.81$ & 2.43 & $0.99-5.97$ & 0.04 \\
\hline$\uparrow$ LDL-C & 1.09 & $0.22-1.29$ & 1.78 & $0.63-5.02$ & $>0.05$ \\
\hline
\end{tabular}


the HDL-C level reduction irrespective of the VDR gene alleles condition 1.83 times (OR = 2.37; OR 95\% Cl: $1.02-5.51 ; p=0.04)$ and 1.9 times $(O R=2.43 ;$ OR $95 \%$ Cl: 0.99-5.97; $p=0.04)$.

The EAH risk considering lipid metabolism parameters and AGT gene (rs699) polymorphism was assessed as well (Table 4). The EAH risk increases 4.5 times as much in the TC genotype carriers in case of lowered HDL-C level (OR = 6.43; OR 95\% Cl: 1.33-30.99; $p=0.01)$.

Table 4: Lipids values as predictors of essential arterial hypertension in observed population depending on AGT gene (rs699) polymorphism

\begin{tabular}{|c|c|c|c|c|c|}
\hline \multirow[t]{2}{*}{ Potential risk factor } & \multicolumn{5}{|c|}{ Parameters } \\
\hline & RR & $95 \% \mathrm{CI} R \mathrm{RR}$ & OR & $95 \%$ CI RR & $\mathrm{p}$ \\
\hline \multicolumn{6}{|l|}{ TT genotype } \\
\hline$\uparrow \mathrm{TC}$ & 0.8 & $0.42-1.53$ & 0.5 & $0.07-3.85$ & $>0.05$ \\
\hline$\uparrow$ TGs & 1.2 & $0.51-2.83$ & 1.5 & $0.23-9.8$ & $>0.05$ \\
\hline$\downarrow$ HDL-C & 0.67 & $0.32-1.39$ & 0.33 & $0.04-2.52$ & $>0.05$ \\
\hline$\uparrow$ LDL-C & 0.9 & $0.73-1.11$ & 0 & - & $>0.05$ \\
\hline \multicolumn{6}{|l|}{ TC genotype } \\
\hline$\uparrow \mathrm{TC}$ & 0.93 & $0.70-1.22$ & 0.74 & $0.24-2.28$ & $>0.05$ \\
\hline$\uparrow$ TGs & 0.57 & $0.26-1.21$ & 0.45 & $0.15-1.32$ & $>0.05$ \\
\hline$\downarrow$ HDL-C & 4.53 & $1.13-18.26$ & 6.43 & $1.33-30.99$ & 0.01 \\
\hline$\uparrow$ LDL-C & 1.09 & $0.91-1.30$ & 2.32 & $0.48-11.29$ & $>0.05$ \\
\hline \multicolumn{6}{|l|}{ CC genotype } \\
\hline$\uparrow \mathrm{TC}$ & 0.87 & $0.51-1.47$ & 0.69 & $0.17-2.81$ & $>0.05$ \\
\hline$\uparrow$ TGs & 0.92 & $0.39-2.17$ & 0.88 & $0.22-3.52$ & $>0.05$ \\
\hline$\downarrow$ HDL-C & 1.18 & $0.41-3.45$ & 1.27 & $0.28-5.68$ & $>0.05$ \\
\hline$\uparrow$ LDL-C & 1.08 & $0.73-1.58$ & 1.36 & $0.28-6.68$ & $>0.05$ \\
\hline \multicolumn{6}{|l|}{$C$ allele } \\
\hline$\uparrow \mathrm{TC}$ & 0.92 & $0.72-1.18$ & 0.75 & $0.31-1.78$ & $>0.05$ \\
\hline$\uparrow \mathrm{TGs}$ & 0.68 & $0.38-1.2$ & 0.57 & $0.24-1.31$ & $>0.05$ \\
\hline$\downarrow$ HDL-C & 2.37 & $0.79-7.15$ & 3.07 & $0.81-11.63$ & $>0.05$ \\
\hline$\uparrow$ LDL-C & 1.1 & $0.92-1.3$ & 1.85 & $0.61-5.56$ & $>0.05$ \\
\hline
\end{tabular}

Analysis of lipid values as EAH predictors in observed population considering sex demonstrated that HDL-C reduction and LDL-C elevation increase this risk 2.4 times (OR = 3.27; OR 95\% Cl: 1.22-8.73; $\mathrm{p}=0.01)$ and 1.24 times $(\mathrm{OR}=3.67$; OR $95 \% \mathrm{Cl}$ : $1.27-10.6 ; p=0.01$ ) in women, respectively (Table 5).

Table 5: Lipids values as predictors of essential arterial hypertension in observed population depending on sex

\begin{tabular}{|c|c|c|c|c|c|}
\hline \multirow[t]{2}{*}{ Potential risk factor } & \multicolumn{5}{|c|}{ Parameters } \\
\hline & RR & $95 \% \mathrm{Cl}$ RR & OR & $95 \% \mathrm{Cl}$ RR & $p$ \\
\hline \multicolumn{6}{|l|}{$\uparrow \uparrow \mathrm{TC}$} \\
\hline M & 0.7 & $0.46-1.06$ & 0.3 & $0.07-1.18$ & $>0.05$ \\
\hline $\mathrm{F}$ & 0.94 & $0.74-1.2$ & 0.82 & $0.34-1.95$ & $>0.05$ \\
\hline \multicolumn{6}{|l|}{$\uparrow \mathrm{TGs}$} \\
\hline M & 1.57 & $0.81-3.06$ & 2.33 & $0.67-7.95$ & $>0.05$ \\
\hline $\mathrm{F}$ & 1.44 & $0.91-2.3$ & 1.95 & $0.88-4.3$ & $>0.05$ \\
\hline \multicolumn{6}{|l|}{$\downarrow \mathrm{HDL}-\mathrm{C}$} \\
\hline$M$ & 1.4 & $0.58-3.35$ & 1.64 & $0.45-5.94$ & $>0.05$ \\
\hline $\mathrm{F}$ & 2.41 & $1.1-5.28$ & 3.27 & $1.22-8.73$ & 0.01 \\
\hline \multicolumn{6}{|l|}{$\uparrow \mathrm{LDL}-\mathrm{C}$} \\
\hline M & 0.81 & $0.66-1.0$ & 0 & - & $>0.05$ \\
\hline $\mathrm{F}$ & 1.24 & $1.01-1.51$ & 3.67 & $1.27-10.6$ & 0.01 \\
\hline
\end{tabular}

\section{Discussion}

$\mathrm{EAH}$ is a multifactorial disease that includes such factors as dyslipidemia, smoking, DM [10], [13], and obesity [13], [14]. Genes determine approximately $20-60 \%$ of BP variability and some peculiarities of hypertensive-mediated organs damage in different populations [6], [7], [8], [11], [15].

As for the AGT gene, SNP rs699 is a $\mathrm{T}$ to $C$ substitution in the exon 2 , resulting in a functional methionine $(\mathrm{M})$ to threonine $(\mathrm{T})$ exchange at codon 268 (M268T). Previously, rs699 was positioned to the amino acid 235 and the SNP is, therefore, also referred to as $\mathrm{M} 235 \mathrm{~T}$. The rs699 threonine variant is associated with higher plasma AGT levels and BP [15].

The VDR gene is located on chromosome 12q13.1, and SNPs of this gene can affect BP. One of the most studied SNPs of the VDR gene is Fok I (rs228570 or rs10735810). Fok I polymorphism can generate truncated proteins and is associated with an increased risk for hypertension. Fok I polymorphism is caused by a thymine-to-cytosine transition, which leads to a translational frameshift characterized by an extension of the open reading frame to the next initiation codon (ATG), resulting in the synthesis of a truncated 424-amino acid protein [16].

The number of studies dealing with the association of lipid metabolism and VDR and AGT genes polymorphism in patients with $E A H$ is limited. Khamlaoui et al. indicated the relation of $A G T$ genotypes with dyslipidemia, that is, reliably higher parameters of TC and LDL-C among the TT genotype carriers [17]. Borai et al. stated that patients with ischemic heart disease present a considerable difference between AGT genotypes concerning HDL-C with the value $\mathrm{p}<0.05$ [8]. Junusbekov also affirmed that the CC genotype of rs699 was significantly related to HDL-C levels $(p=0.020)$ [18]. Results presented by Jia et al. indicated that VDR polymorphism correlates with the risk of an increased LDL-C level [19]. The studies carried out by Aline Hajj found that men carriers of the mutation VDR genotype possess a higher level of TGs and lower level of HDL-C ( $p=0.0036$ and $p=0.005)$ [20].

The optimal approach to investigate patients who present EAH symptoms depending on genetics' polymorphism remains controversial. Our prospective case-control clinical research was randomized and designed to test the hypothesis that genes polymorphism VDR (rs10735810, rs222857) and AGT (rs699) would associate with lipids metabolism pathogenic pathway. Therefore, further investigation of the gene-environment interactions and gene-metabolism associations still needs to be provided and extended.

\section{Conclusions}

T allele of $A G T$ gene is associated with a lower level of HDL-C in hypertensive men and a higher level of TGs in EAH women. HDL-C lowered level increases the $\mathrm{EAH}$ risk 4.5 times as much in the TC genotype 
carriers of $A G T$ gene ( $r$ 6999) (OR $=6.43 ; \mathrm{p}=0.01$ ) and $1.83(\mathrm{OR}=2.37 ; \mathrm{p}=0.04)$ and 1.9 times $(\mathrm{OR}=2.43$; $p=0.04$ ) irrespective of the VDR gene allele condition. In women, the HDL-C low level and LDL-C elevation increase $\mathrm{EAH}$ risk 2.4 times $(\mathrm{OR}=3.27 ; \mathrm{p}=0.01)$ and 1.24 times $(O R=3.67 ; p=0.01)$, respectively.

\section{References}

1. Mach F, Baigent C, Catapano A, Koskinas K, Casula M, Badimon L, et al. 2019 ESC/EAS Guidelines for the management of dyslipidaemias: Lipid modification to reduce cardiovascular risk: The Task Force for the management of dyslipidaemias of the European society of cardiology (ESC) and European atherosclerosis society (EAS). Eur Heart J. 2020;41(1):111-88. https://doi.org/10.1093/eurheartj/ehz455

PMid:31504418

2. Wermelt JA, Schunkert $H$. Management of arterial hypertension. Herz. 2017;42(5):515-26. http://doi.org/10.1007/ s00059-017-4574-1

PMid:28555286

3. Rossier BC, Bochud $M$, Devuyst $O$. The hypertension pandemic: An evolutionary perspective. Physiology (Bethesda). 2017;32(2):112-25. http://doi.org/10.1152/physiol.00026.2016 PMid:28202622

4. Changjun L, Qinghua C, JiaZ, Wenshu C. Effects of slow breathing rate on heart rate variability and arterial baroreflex sensitivity in essential hypertension. Medicine. 2018;97(18):e0639. http://doi. org/10.1097/MD.0000000000010639

PMid:29718876

5. Burnier M. Controversies in the management of patients with arterial hypertension. Kardiol Pol. 2019;25;77(10):902-7. http:// doi.org/10.33963/KP.15002

PMid:31571674

6. Sydorchuk LP, Dzhuryak VS, Sydorchuk AR, Levytska SA, Knut RP, Sokolenko MO, et al. Association of lipids' metabolism disorders with aldosterone synthase CYP11B2 (-344C/T) gene polymorphism in hypertensive patients depending on glomerular filtration rate. Pharmacol Online. 2020;2:230-42.

7. Dzhuryak V, Sydorchuk L, Sydorchuk A, Kamyshnyi O, KshanovskaA, LevytskaS, etal.Thecytochrome11B2aldosterone synthase gene CYP11B2 (RS1799998) polymorphism associates with chronic kidney disease in hypertensive patients. Biointerface Res Appl Chem. 2020;10(3):5406-11. https://doi. org/10.33263/BRIAC103.406411

8. Borai I, Hassan N, Shaker O, Ashour E, Badrawy M, Fawzi O, et al. Synergistic effect of ACE and AGT genes in coronary artery disease. Beni Suef Univ J Basic Appl Sci. 2018;7(1):111-7. https://doi.org/10.1016/j.bjbas.2017.09.003

9. Butler MG. Genetics of hypertension. Current status. J Med Liban. 2010;58(3):175-8.

PMid:21462849

10. Sydorchuk L, Dzhuryak V, Sydorchuk A, Levytska S, Petrynych V, et al. The cytochrome 11B2 aldosterone synthase gene rs1799998 single nucleotide polymorphism determines elevated aldosterone, higher blood pressure, and reduced glomerular filtration, especially in diabetic female patients. Endocr Regul. 2020;54(3):217-26. http://doi.org/10.2478/ enr-2020-0024

11. Repchuk Y, Sydorchuk LP, Sydorchuk AR, Fedonyuk LY, Kamyshnyi O, Korovenkova $\mathrm{O}$, et al. Blood pressure, obesity and diabetes mellitus linkage with angiotensinogen gene (AGT 704T>C/rs699) polymorphism in hypertensive patients. Bratislava Med J. 2021;122(10):715-20. http:// doi. org/10.4149/ bll_2021_114.

12. Mach F, Baigent $C$, Catapano AL, Koskinas KC, Casula M, Badimon L, et al. $2019 \mathrm{ESC} / \mathrm{EAS}$ Guidelines for the management of dyslipidaemias: Lipid modification to reduce cardiovascular risk. Eur Heart J. 2020;41(1):111-188. http://doi.org/10.1093/ eurheartj/ehz455

13. Sydorchuk LP, Serdulets $Y I$, Sydorchuk AR. The polymorphism of matrilin-3 (rs77245812) and interleukin-10 (rs1800872) genes in osteoarthritis patients with arterial hypertension, obesity and Type 2 diabetes mellitus. Arch Balk Med Union. 2017;52(4):422-9.

14. Sydorchuk LP, Sokolenko AA, Sydorchuk AR, Kryklyvets LG, Biryuk IG, Fliundra IG, et al. Insulin resistance in patients with arterial hypertension and abdominal obesity depending on ace and ppar- $\gamma 2$ genes polymorphism: A new opinion concerning an old problem. New Armenian Med J. 2015;9:43-51.

15. Makuc J, Šeruga $M$, Završnik $M$, Cilenšek $I$, Petrovič $D$. Angiotensinogen (AGT) gene missense polymorphisms (rs699 and rs4762) and diabetic nephropathy in Caucasians with Type 2 diabetes mellitus. Bosn J Basic Med Sci. 2017;17(3):262- 7. http://doi.org/10.17305/bjbms.2017.1823

PMid:28488548

16. de Oliveira Costa Nunes IF, de Pinho FA, do Socorro Pires e Cruz M, de Azevedo Paiva A, de Carvalho CM. Influence of polymorphism of Vitamin D receptor (Fok I) on hypertension. Braz Arch Biol Technol. 2020;63:403. https://doi. org/10.1590/1678-4324-2020190403

17. Khamlaoui W, Mehri S, Hammami S, Elosua R, Hammami M. Association of angiotensin-converting enzyme insertion/deletion (ACE I/D) and angiotensinogen (AGT M235T) polymorphisms with the risk of obesity in a Tunisian population. J Renin Angiotensin Aldosterone Syst. 2020;21(2):1470320320907820. http://doi.org/10.1177/1470320320907820 PMid:32356512

18. Junusbekov $Y$, Bayoglu B, Cengiz M, Dirican A, Arslan C. AGT rs699 and AGTR1 rs5186 gene variants are associated with cardiovascular-related phenotypes in atherosclerotic peripheral arterial obstructive disease. Ir J Med Sci. 2020;189(3):885-94. https://doi.org/10.1007/s11845-019-02166-6

PMID: 31858452

19. Jia J, Tang $\mathrm{Y}$, Shen $\mathrm{C}$, Zhang $\mathrm{N}$, Ding $\mathrm{H}$, Zhan $\mathrm{Y}$, et al Vitamin D receptor polymorphism rs2228570 is significantly associated with risk of dyslipidemia and serum LDL levels in Chinese Han population. Lipids Health Dis. 2018;17:193. https:// doi. org/10.1186/s12944-018-0819-0 PMid:30119682

20. Hajj A, Chedid R, Chouery E, Megarbané A, Gannagé-Yared MH Relationship between Vitamin $D$ receptor gene polymorphisms, cardiovascular risk factors and adiponectin in a healthy young population. Pharmacogenomics. 2016;17(15):1675-86. http:// doi.org/10.2217/pgs-2016-0045

PMid:27672714 